\title{
N-3 Fatty Acids Stimulate Intracellular Degradation of Apoprotein B in Rat Hepatocytes
}

\author{
Hongxing Wang, Xiaoli Chen, and Edward A. Fisher \\ Department of Biochemistry, Medical College of Pennsylvania, Philadelphia, Pennsylvania 19129
}

\begin{abstract}
When rat hepatocytes were incubated with albumin complexed to the n-3 fatty acids, eicosapentaenoic acid (EPA) and docosahexaenoic acid (DHA), rather than to oleic acid (OA), the secretion of newly synthesized apoprotein B100 (apoB100) or B48 (apoB48) was reduced, despite stimulation of cellular triglyceride synthesis by all three fatty acids. When pulse-chase studies of apoB synthesis and secretion were performed in the presence of OA, EPA, or DHA, there were no significant changes in the initial synthetic rates of either apoB species. However, during the chase period, the total recovery of labeled apoB100 and apoB48 from the cell and medium was less in the n-3 fatty acid groups, so that by $150 \mathrm{~min}$, approximately half as much labeled apoB was recovered as in the OA group. Overall, the decreased accumulation in medium of labeled apoB in the presence of EPA and DHA could be quantitatively accounted for by increased degradation of intracellular apoB. Thus, in the primary hepatocyte, apoB degradation is not constitutive, but can be regulated by n-3 fatty acids. (J. Clin. Invest. 1993. 91:1380-1389.) Key words: apoprotein B48 • apoprotein B100• apoprotein $B$ degradation - immunoprecipitation - n-3 fatty acids
\end{abstract}

\section{Introduction}

The effects of the n-3 fatty acids found in fish oils on mammalian lipoprotein metabolism have been extensively studied because of their potential therapeutic benefits. There is a general consensus ( reviewed in references 1 and 2) that enrichment of diets with either eicosapentaenoic acid (EPA) ${ }^{1}$ or docosahexaenoic acid (DHA), two major fatty acids common in fish oils, results in a lowering of plasma triglyceride levels. However, there is no agreement concerning their mechanism of action. Hypotheses advanced thus far include $(a)$ decreased synthesis

A portion of this work was presented at the Scientific Sessions of the American Heart Association held in New Orleans, LA, 16-19 November 1992.

Address reprint requests to Dr. Edward A. Fisher, Department of Biochemistry, Medical College of Pennsylvania, 2900 Queen Lane, Philadelphia, PA 19129.

Received for publication 7 February 1992 and in revised form 4 November 1992.

1. Abbreviations used in this paper: DHA, docosahexaenoic acid; EPA, eicosapentaenoic acid; HepG2, a human hepatocellular carcinoma cell line; OA, oleic acid.

J. Clin. Invest.

(c) The American Society for Clinical Investigation, Inc. $0021-9738 / 93 / 04 / 1380 / 10 \quad \$ 2.00$

Volume 91, April 1993, 1380-1389 of hepatic triglycerides $(3),(b)$ increased clearance of triglyceride-rich lipoproteins by either enhanced lipolysis by lipoprotein lipase (4) or increased LDL receptor activity (5), and (c) inhibition of the assembly or secretion of newly synthesized apoB-containing particles (6-8).

In this article, we have focused primarily on the last mechanism by studying, in rat primary hepatocytes, the metabolism of newly synthesized apoB after exposure of the cells to EPA or DHA complexed to albumin (BSA). The results were compared to two control treatments; BSA alone and BSA complexed to oleic acid (OA), a model fatty acid precursor of triglycerides. Because rat liver can edit the mRNA for apoB and produce lipoprotein particles containing either the larger (apoB100) or smaller (apoB48) protein species (9-12), we were able to examine the separate effects of $n-3$ fatty acids on newly synthesized apoB100, apoB48, and total apoB.

As will be described, we have determined the effects in rat hepatocytes of incubation with different fatty acid-BSA complexes on three aspects of the cellular metabolism of apoB: $(a)$ the steady-state level of apoB in cells and conditioned media; (b) the synthetic capacity of the cells for apoB, by measuring the apoB mRNA level and the initial synthetic rate of apoB; and $(c)$ the degradation of apoB as assessed by pulse-chase analysis. The data clearly demonstrated that the intracellular degradation of apoB increased in the EPA and DHA groups, and that this increase can quantitatively account for the decrease in the secretion of newly synthesized $\mathrm{apoB}$ by hepatocytes incubated with the n-3 fatty acids.

\section{Methods}

All chemical reagents were the highest grade commercially available and purchased from Sigma Chemical Co. (St. Louis, MO) unless indicated otherwise. Male Sprague-Dawley rats (200-225 g) were purchased from Ace Animals (Boyertown, PA).

\section{Cell culture}

Ad-lib fed animals were killed in the morning and liver cells were isolated by collagenase perfusion using $0.225 \mathrm{mg} / \mathrm{ml}$ collagenase (Worthington Biochemical Corp., Freehold, NJ) dissolved in Krebs-Ringer buffer containing calcium $(1.66 \mathrm{mM})$. Hepatocytes were purified by differential centrifugation through a 45\% Percoll solution and viability determined by exclusion of ethidium bromide stain. Under a fluorescence microscope, the nuclei of damaged cells were seen to be clearly fluorescent. Typically, $>85 \%$ of the cells excluded ethidium bromide.

Cells were plated at a density of $2 \times 10^{6}$ cells $/ \mathrm{ml}$ on $60-\mathrm{mm}$ culture dishes previously coated with poly-D-lysine in modified M199 medium (M199, 1\% FBS, $1 \mathrm{mM}$ nicotinamide, $0.1 \mathrm{nM}$ insulin, $3 \mathrm{mg} / \mathrm{ml}$ choline, $1.1 \%$ L-glutamine, $1 \% \mathrm{BSA}$ ). After a 4-h attachment period, the medium was changed to modified M199-10\% FBS, and the cells were incubated overnight. The next morning, the medium was removed and the cell monolayers washed three times with serum-free medium and then incubated with experimental media as described below. 


\section{Antisera}

A monospecific rabbit anti-rat apoB polyclonal antiserum was kindly provided by Drs. Janet D. Sparks and Charles E. Sparks (University of Rochester). For some experiments, goat anti-rat apoB polyclonal antiserum was used. It was prepared in this laboratory as follows: The fraction containing the $d<1.020$ lipoproteins was obtained by ultracentrifugation from pooled sera of sucrose-fed rats. The lipoproteins were delipidated, the resulting apoproteins separated by column chromatography, and apoB purified as previously described (13). ApoB (0.5 mg) was mixed with Ribi adjuvant (Immunochem Research Inc., Hamilton, MT) and injected into the hindquarters $(0.25 \mathrm{mg}$ per side $)$ of a goat. Immunizations and boosters were performed according to the manufacturer's protocol. The titer and specificity of the resulting antibodies were examined by Western blot analysis (14). The goat antiserum had similar immunoreactivity and specificity as that of the rabbit. Pilot studies were performed to determine the titer of antiserum that would quantitatively precipitate radiolabeled apoB from cell lysate and conditioned medium. An initial immunoprecipitation was followed by a second immunoprecipitation of the material that remained in the supernatant. At a rabbit or goat antiserum titer of 1:300 in both immunoprecipitation reactions, no additional radiolabeled apoB was recovered from lysate or medium samples after the first immunoprecipitation.

For the immunoprecipitation of newly synthesized rat albumin, a monospecific polyclonal goat antiserum was purchased from United States Biochemical Corp. (Cleveland, $\mathrm{OH}$ ) and reconstituted as directed by the manufacturer.

\section{Metabolic labeling of hepatic proteins}

Steady-state studies. It had been previously reported that incubation of rat primary hepatocytes with $\left[{ }^{35} \mathrm{~S}\right]$ methionine for at least $2 \mathrm{~h}$ will maximally label the intracellular apoB pool (15). In the morning after hepatocyte isolation, cells were incubated $4 \mathrm{~h}$ in $3 \mathrm{ml}$ of RPMI $1640 \mathrm{me}$ dium containing the following: $150 \mu \mathrm{Ci}\left[{ }^{35} \mathrm{~S}\right]$ methionine $(1,100 \mathrm{Ci} /$ $\mathrm{mmol}$, New England Nuclear, Boston, MA), and either BSA (0.16 $\mathrm{mM}$ ) or fatty acid (FA)-BSA complex (0.8 mM OA, EPA, or DHA; $0.16 \mathrm{mM}$ BSA ). Incorporation of label into the two species of apoB was determined by immunoprecipitation analysis as described below.

Pulse-chase studies. In the morning after hepatocyte isolation, cells were incubated for $2 \mathrm{~h}$ with FA-BSA complexes or BSA alone in $3.0 \mathrm{ml}$ of methionine-free medium ( RPMI 1640D) supplemented with $10 \mu \mathrm{M}$ L-methionine, then changed to $2 \mathrm{ml}$ of the same medium that was not supplemented with cold methionine. Incubation was continued for another $2 \mathrm{~h}$. Without changing the medium, $200 \mu \mathrm{Ci}$ of $\left[{ }^{35} \mathrm{~S}\right]$ methionine in $100 \mu \mathrm{l}$ of RPMI $1640 \mathrm{D}$ were then added to each dish. Incubation with the label was continued for exactly $15 \mathrm{~min}$, after which the medium from each dish was quickly withdrawn and the cell monolayers washed three times with RPMI 1640D medium supplemented with 10 $\mathrm{mM}$ L-methionine. The cells were then incubated in RPMI 1640D medium containing $10 \mathrm{mM}$ L-methionine and either FA-BSA complexes or BSA alone for the various chase periods (as noted in the appropriate tables and figures). Immunoprecipitation analysis of labeled cellular and secreted apoB was performed as described below.

In some labeling studies, cycloheximide was employed to determine whether the effects of EPA and DHA required active protein synthesis. Two protocols were used. In protocol 1 , after plating, hepatocytes were labeled to steady-state by incubation with $\left[{ }^{35} \mathrm{~S}\right]$ methionine ( $100 \mu \mathrm{Ci}$ per dish) in serum-free medium (RPMI $1640-0.2 \% \mathrm{BSA}$; medium A) for $14 \mathrm{~h}$. The medium was then withdrawn and the cells washed three times with medium A containing $10 \mu \mathrm{g} / \mathrm{ml}$ cycloheximide and $10 \mathrm{mM}$ L-methionine and incubated for $3 \mathrm{~h}$ in RPMI 1640 medium containing $10 \mu \mathrm{g} / \mathrm{ml}$ cycloheximide, $10 \mathrm{mM}$ L-methionine, and either FA-BSA complex or BSA alone. Thus, protein synthesis inhibition was concurrent with exposure to the treatment media.

In protocol 2, cells were first incubated for $4 \mathrm{~h}$ with $\left[{ }^{35} \mathrm{~S}\right]-$ methionine $(100 \mu \mathrm{Ci} /$ dish $)$ in the presence of either an OA or EPA
FA-BSA complex. The cells were then washed in medium A and incubated for $3 \mathrm{~h}$ in RPMI 1640 medium containing $10 \mu \mathrm{g} / \mathrm{ml}$ cycloheximide, $10 \mathrm{mM}$ L-methionine, and FA-BSA complex. Thus, protein synthesis was inhibited after FA treatment had begun.

\section{Immunoprecipitation analysis}

At the conclusion of each experiment, the medium from each dish was transferred into an individual tube and centrifuged for $5 \mathrm{~min}$ at 1,000 rpm in a table top centrifuge (Beckman Instruments, Inc., Fullerton, CA) to remove debris. The cell monolayers were washed three times with salt-balanced Hanks' solution (or, in the case of pulse-chase studies, with RPMI 1640D medium containing $10 \mathrm{mM}$ L-methionine), and then solubilized by addition of $1.0 \mathrm{ml}$ of detergent buffer (buffer $\mathrm{C}$ : $0.01 \mathrm{M} \mathrm{Na}$ phosphate [ $\mathrm{pH} 7.4$ ] $, 0.125 \mathrm{M} \mathrm{NaCl}, 1 \%$ [vol/vol] Triton $\mathrm{X}-100,1 \%$ [wt/vol] Na deoxycholate and $1 \%$ [wt/vol] lithium dodecyl sulfate). Protease inhibitors $(2.0 \mathrm{mM}$ benzamidine, $1.0 \mathrm{mM}$ phenylmethylsulfonyl fluoride, $20 \mu \mathrm{g} / \mathrm{ml}$ aprotinin, and $20 \mu \mathrm{g} / \mathrm{ml}$ leupeptin) were freshly added to buffer $\mathrm{C}$ just before use. The dishes were placed at $37^{\circ} \mathrm{C}$ for $15 \mathrm{~min}$ with shaking. The cell lysates were then pipetted into glass tubes and heated at $80^{\circ} \mathrm{C}$ for $1 \mathrm{~h}$ and then reheated at $95^{\circ} \mathrm{C}$ for $5 \mathrm{~min}(16)$. A 0.5 -ml aliquot of lysate was diluted with $0.5 \mathrm{ml}$ of a solution of $0.01 \mathrm{M}$ Tris $/ \mathrm{HCl}(\mathrm{pH} \mathrm{7.4)}$ and $0.15 \mathrm{M} \mathrm{NaCl}$ and used in the subsequent steps. Media samples were diluted by mixing a $0.5-\mathrm{ml}$ aliquot with $0.5 \mathrm{ml}$ buffer $\mathrm{C}$.

The diluted lysate and media samples were then treated to remove nonspecific proteins. To each tube was added $0.5 \mathrm{ml}$ of a $1 \%$ BSA solution (in phosphate-buffered saline) containing $20 \mu$ l of either nonimmune rabbit or goat serum (as appropriate) and either $40 \mu$ l of protein A cells (Immunoprecipitin, Bethesda Research Laboratories, Gaithersburg, MD) or $100 \mu$ l of $12.5 \%$ protein G-Sepharose 4B Fast Flow beads, respectively. After incubation at $4^{\circ} \mathrm{C}$ for $1.5 \mathrm{~h}$, nonspecifically bound proteins were pelleted by centrifugation at $2,800 \mathrm{rpm}$ for $10 \mathrm{~min}$ and the supernatant was transferred to a fresh tube.

To immunoprecipitate apoB, antiserum (either rabbit or goat) was added to the supernatant at a final dilution of $1: 300$. The tubes were rotated overnight at $4^{\circ} \mathrm{C}$. In the morning, either $40 \mu \mathrm{l}$ protein A cells (when rabbit antiserum used) or $100 \mu$ l of protein $\mathrm{G}$ beads (when goat antiserum used) were added and the incubation continued for $1 \mathrm{~h}$ at $4^{\circ} \mathrm{C}$. Protein A-antibody-apoB complexes were collected by centrifugation at $2,800 \mathrm{rpm}$ for $10 \mathrm{~min}$. The pellets were washed three to five times with a buffer that was $0.01 \mathrm{M}$ Tris- $\mathrm{HCl}[\mathrm{pH} 7.4], 0.15 \mathrm{M} \mathrm{NaCl}$, $0.15 \%$ [wt/wt] SDS, $0.1 \%$ [vol/vol] Triton X-100, and 2 mM EDTA. For protein $\mathrm{G}$-antibody-apoB complexes, the procedure was identical except the washing buffer was $0.1 \mathrm{M}$ Tris/ $\mathrm{HCl}[\mathrm{pH} 9.0], 0.5 \mathrm{M} \mathrm{LiCl}$, and $1 \%$ [ $\mathrm{vol} / \mathrm{vol}] 2$-mercaptoethanol. For analysis of newly secreted rat albumin by the goat antiserum directed against this protein, the immunoprecipitation procedures employing protein- $G$ were applied to medium samples using the reconstituted reagent at a final dilution of 1:150.

Antibody-antigen complexes were released from the pellets by adding $150 \mu \mathrm{l}$ of buffer containing $62.5 \mathrm{mM}$ Tris $/ \mathrm{HCl}$ [ $\mathrm{pH} \mathrm{6.8],2 \%} \mathrm{[wt/}$ vol] SDS, $5 \%$ [ vol/vol] 2-mercaptoethanol, $20 \%$ [ vol/vol] glycerol, and $10 \mathrm{mM}$ dithiothreitol and heating to $95^{\circ} \mathrm{C}$ for $5 \mathrm{~min}$. After centrifugation to remove any insoluble material $(2,800 \mathrm{rpm}, 10 \mathrm{~min})$, the supernatants were analyzed by electrophoresis in a $3.5 \%$ polyacrylamide-18\% glycerol gel (17). After staining and fixing, the gel was enhanced in fluor (Autofluor, National Diagnostics, Manville, NJ). The enhanced gel was dried and exposed to XAR-5 film (Eastman Kodak Co., Rochester, NY) at $-70^{\circ} \mathrm{C}$.

Because the response of photographic film has both a high threshold and a low capacity, weak and strong fluorographic signals are often inaccurate reflections of the true amount of radioactivity incorporated into proteins and are appropriate for qualitative comparisons only. Therefore, when reliable quantitation of labeled apoB48, apoB100, and albumin was necessary, the appropriate radioactive bands were located by fluorography, cut out, and assayed by scintillation counting as described (18). 


\section{Triglyceride synthesis}

Cells were maintained for $6 \mathrm{~h}$ in the presence of $\left[1,2,3-{ }^{3} \mathrm{H}\right]$ glycerol (specific activity of $200 \mathrm{mCi} / \mathrm{mmol}$; New England Nuclear) and either BSA or FA-BSA complexes. Then, the conditioned medium was collected, the cell monolayer washed with PBS, and the total cellular lipids extracted with $4 \mathrm{ml}$ of isopropanol. The extract was evaporated under $\mathrm{N}_{2}$ at $60^{\circ} \mathrm{C}$ and the dried lipids dissolved in $400 \mu \mathrm{l}$ of isopropanol. An aliquot of $100 \mu \mathrm{l}$ of sample was then extracted with $4 \mathrm{ml}$ of Dole's solvent (isopropanol/heptane/0.5 M sulfuric acid; 40:10:1), $100 \mu \mathrm{l}$ of glyceryl trioleate $(2 \mathrm{mg} / \mathrm{ml}), 2.25 \mathrm{ml}$ of heptane, and $1.75 \mathrm{ml}$ of $\mathrm{dH}_{2} \mathrm{O}$. The extracted lipids were mixed with $3 \mathrm{ml}$ of Dole's lower phase solvent (lower phase of a mixture of Dole's solvent $/ \mathrm{dH}_{2} \mathrm{O} /$ heptane; 1.67:1:1), and the resulting upper phase dried as above. ScintiVerse BD (Fisher Scientific Co., Fair Lawn, NJ) was added $(10 \mathrm{ml})$ and after vortexing, the amount of labeled glycerol incorporated into triglycerides was determined by scintillation counting.

To measure the incorporation of labeled glycerol into secreted triglycerides, conditioned medium $(1 \mathrm{ml})$ was extracted with $8 \mathrm{ml}$ of Dole's solvent, $200 \mu \mathrm{l}$ of glyceryl trioleate, $4.5 \mathrm{ml}$ of heptane, and 3.5 $\mathrm{ml}$ of $\mathrm{dH}_{2} \mathrm{O}$. The extracted lipids were mixed with $6 \mathrm{ml}$ of Dole's lower phase solvent, and the resulting upper phase treated as above.

Thin-layer chromatography confirmed that for both the cellular and medium samples, $>95 \%$ of the extracted radioactive lipids were triglycerides.

\section{$R N A$ isolation and quantitation}

Total RNA was isolated from hepatic cells at the conclusion of the experiments using a guanidinium thiocyanate-based procedure (19) as previously described (20).

RNA samples were blotted onto nylon membranes (Nytran, Schleicher \& Schuell, Inc., Keene, NH), using a Bio-Rad Laboratories (Richmond, CA) manifold following the manufacturer's protocol. Hybridizations were performed using ${ }^{32} \mathrm{P}$-labeled DNA probes (random primer method [21]) for apoB (provided by Dr. A. J. Lusis, University of California, Los Angeles), albumin (provided by Dr. T. Sargent, National Institutes of Health), and $\beta$-actin (provided by Dr. D. Friedman, University of Texas). Unbound probes were washed under stringent conditions $(0.1 \times \mathrm{SSC}[0.015 \mathrm{M} \mathrm{NaCl}, 0.0015 \mathrm{M} \mathrm{Na}$ citrate $], 1 \%$ SDS, $55^{\circ} \mathrm{C}$ ), and the membranes exposed to XAR-5 film at $-70^{\circ} \mathrm{C}$. The intensities of the signals on the resulting autoradiograms were quantitated by densitometry.

\section{Other methods}

Protein was measured by the Lowry procedure (22) using BSA as the standard. Labeling of total cellular and medium protein was determined after TCA-phosphotungstic acid precipitation as previously described (23). All results were normalized to the same specific activity of total cellular protein.

\section{Statistical analysis}

The intracellular data were transformed to $\log _{10}$ percentage recoveries and modeled by regression analysis using Quattro Pro software (Borland, Scotts Valley, CA). Equality of the slopes of the regression lines was analyzed by a modified $t$ test (24). Other data were analyzed by either Student's $t$ test or the analysis of variance, using the InStat programs (GraphPad Software, San Diego, CA).

\section{Results}

Steady-state studies. In initial experiments we confirmed that the secretion by the rat hepatocyte of newly synthesized apoB was reduced in the presence of $\mathrm{n}-3$ fatty acids (for example, see reference 6). Rat hepatocytes were incubated with BSA (0.16 $\mathrm{mM}$; control condition $)$ or FA-BSA complexes $(0.8 \mathrm{mM}$ final concentration of FA, $0.16 \mathrm{mM} \mathrm{BSA}$ ) for $4 \mathrm{~h}$ in the presence of $\left[{ }^{35} \mathrm{~S}\right]$ methionine and the conditioned media samples subjected

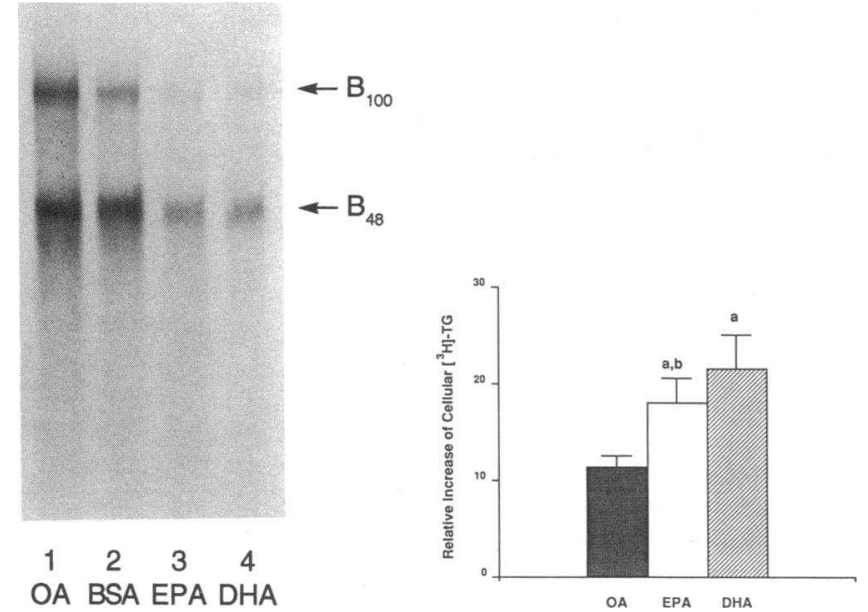

Figure 1. FA effects on rat hepatocyte apoB secretion and cellular triglyceride synthesis. Left: Rat hepatocytes were incubated with either BSA alone or FA-BSA complexes for $4 \mathrm{~h}$ in the presence of $\left[{ }^{35} \mathrm{~S}\right]-$ methionine. Labeled apoB species were isolated from unfractionated conditioned media samples by immunoprecipitation, separated by gel electrophoresis, and visualized by fluorography. Markers on the right are the expected locations of apoB100 and apoB48. The incubation conditions for each lane are shown at the bottom. Right: Rat hepatocytes were incubated as in left panel, except the time was $6 \mathrm{~h}$ and the labeled compound $\left[{ }^{3} \mathrm{H}\right]$ glycerol. Labeled triglycerides were extracted from cell monolayers and quantitated by scintillation counting. Data are expressed as the ratio $( \pm$ SEM $)$ of labeled triglycerides in the presence vs. absence of FA. Results shown are from three separate exper-

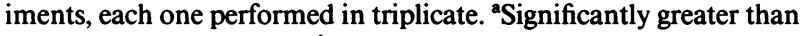
the OA group $(P<0.01)$; ' Significantly less than the DHA group ( $P$ $<0.05)$.

to immunoprecipitation analysis. As shown in Fig. 1, left, there was clearly less labeled apoB present in conditioned media after EPA and DHA treatments (lanes 3 and 4, respectively) as compared to OA or BSA (lanes 1 and 2 , respectively). These reductions were accompanied by decreased secretion of newly synthesized triglycerides (data not shown), in spite of significant stimulation of cellular triglyceride ( $T G$ ) synthesis by EPA or DHA (Fig. 1, right), consistent with recent reports using HepG2 cells and primary hepatocytes (for example, references 6-8). As in our previous studies (8) in the human hepatocellular carcinoma cell line, HepG2, the secretion of newly synthesized albumin in the presence of EPA was comparable to that in the presence of OA $(29,562 \pm 2658$ vs. $28,758 \pm 300 \mathrm{cpm} / \mathrm{mg}$ cell protein, respectively [mean $\pm \mathrm{SD}, n=2]$ ), indicating that the effects of $n-3$ fatty acids on apoB were specific.

We next determined whether the decreased secetion of newly synthesized apoB in the presence of EPA and DHA was accompanied by its intracellular accumulation. Hepatocytes were incubated with BSA or FA-BSA complexes, labeled to steady state with $\left[{ }^{35} \mathrm{~S}\right]$ methionine, and apoB quantitatively immunoprecipitated. As shown in Fig. 2, in the presence of OA, intracellular levels of both apoB100 and apoB48 were higher (approximately twofold, $P<0.05$; Table I) than the levels in cells incubated with EPA, DHA, or BSA. The two n-3 fatty acids affected intracellular apoB levels to different extents. DHA-treated cells had only $\sim 70 \%$ of the apoB as compared to levels in EPA-treated cells $(P<0.05)$. In all groups, the pool of labeled apoB100 was smaller than that of apoB48, consistent 


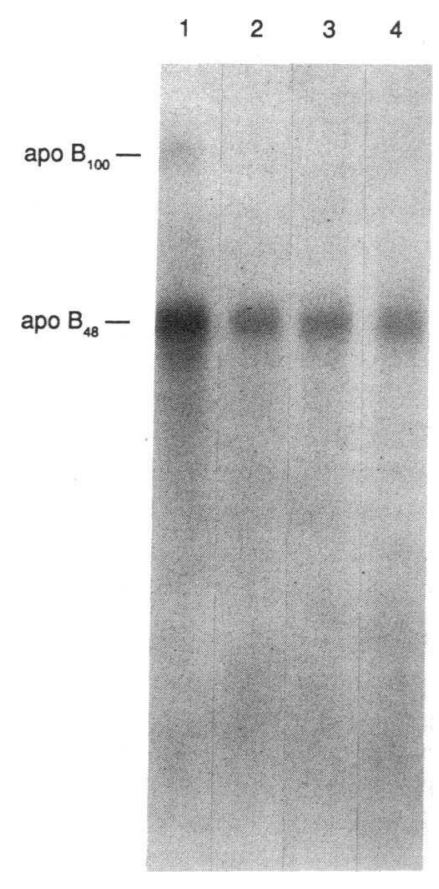

Figure 2. FA effects on intracellular apoB labeled to steady state. Rat hepatocytes were incubated as in Fig. 1 (left). Labeled apoB species were isolated from cell lysates by immunoprecipitation and separated by gel electrophoresis. Gels were enhanced and dried, and apoB signals were visualized by fluorography. Markers on the left indicate the expected position of the indicated apoB species. The treatment conditions for each lane were: $1, \mathrm{OA} ; 2$, BSA alone; 3, EPA; 4, DHA.

with previous reports (for example, references 15 and 16). The ratio of labeled intracellular apoB 100 to apoB48 for each treatment, as calculated from the data in Table I, was $0.31,0.24$, 0.27 , and 0.23 , for OA, BSA, EPA, and DHA, respectively.

The amounts of TCA-phosphotungstic acid-precipitable labeled proteins (per milligram cell protein) in either cell lysates or conditioned media among the groups of cells were not significantly different (data not shown), indicating that the results cannot be explained by either differential uptake of $\left[{ }^{35} \mathrm{~S}\right]$ methionine or toxicity of the $\mathrm{n}-3$ fatty acids relative to $\mathrm{OA}$ or BSA. By considering both the intracellular and extracellular results, it is clear that, as compared to incubation with OA, there was an overall reduction in the level of newly synthesized and secreted apoB in the presence of EPA or DHA.

Table I. Steady-State Levels of Newly Synthesized ApoB in Hepatocytes Incubated with BSA or FA-BSA Complexes

\begin{tabular}{llcl}
\hline FA & \multicolumn{1}{c}{ apoB $_{\text {lowal }}$} & apoB 100 & apoB48 \\
\hline & & $c p m / m g$ cell protein \\
OA & $5603 \pm 727^{*}$ & $1342 \pm 172^{*}$ & $4260 \pm 555^{*}$ \\
BSA & $2545 \pm 533$ & $501 \pm 154$ & $2045 \pm 436$ \\
EPA & $3083 \pm 1023^{\ddagger}$ & $661 \pm 194^{\ddagger}$ & $2423 \pm 838^{\ddagger}$ \\
DHA & $2319 \pm 788$ & $440 \pm 184$ & $1879 \pm 607$
\end{tabular}

Rat hepatocytes were incubated with either BSA alone or FA-BSA complexes for $4 \mathrm{~h}$ in the presence of $\left[{ }^{35} \mathrm{~S}\right]$ methionine. Labeled apoB was isolated from cell lysates by immunoprecipitation and separated by gel electrophoresis. The bands corresponding to apoB100 and apoB48 were removed and the amount of incorporated label determined by scintillation counting. Data are expressed as the mean $( \pm S D) \mathrm{cpm}$ after adjusting for cell protein. Results are from three separate experiments, each one performed in duplicate. * Significantly greater than results in the other groups $(P<0.05)$. ${ }^{\ddagger}$ Significantly greater than results in the DHA group $(P<0.05)$.
Table II. Hepatocyte mRNA Levels after FA-BSA Complex Treatment Relative to Incubation with BSA Alone

\begin{tabular}{lcccc}
\hline & \multicolumn{4}{c}{ FA } \\
\cline { 2 - 4 } mRNA & OA & EPA & DHA & ANOVA* \\
\hline ApoB & $0.98 \pm 0.02$ & $0.94 \pm 0.02$ & $0.94 \pm 0.09$ & $P>0.80$ \\
Actin & $1.10 \pm 0.04$ & $1.21 \pm 0.12$ & $1.14 \pm 0.12$ & $P>0.75$ \\
Albumin & $1.01 \pm 0.06$ & $1.06 \pm 0.05$ & $0.97 \pm 0.02$ & $P>0.40$ \\
& & & & \\
\hline
\end{tabular}

Hepatocytes were incubated for $6 \mathrm{~h}$ in the presence of BSA alone or the indicated FA complexed to BSA. RNA samples were isolated and the mRNA abundances for the three proteins determined for each plate of cells by slot blotting. The results are from four separate experiments, each done at least in duplicate. Data are expressed as the mean ratio $( \pm$ SEM) of the abundance of the particular $m R N A$ in the presence of the indicated fatty acid to the abundance in the absence of the fatty acid (BSA control condition). ${ }^{*} P$ values for the difference among the ratios determined by one-way analysis of variance.

Synthetic rate studies. To determine whether lower steadystate levels of intracellular apoB were due to decreased synthesis or increased degradation, both apoB mRNA levels and the initial synthetic rates of apoB under the different treatment conditions were measured. As summarized in Table II, relative to the BSA control cells, there were no statistically significant differences among fatty acid treatments in the expression of the apoB or control ( $\beta$-actin, albumin) genes.

To determine the initial synthetic rate of apoB, a pulsechase experimental design $(15,16)$ was used. After a 4-h incubation in the different treatment media, cellular proteins were metabolically labeled by incubation in treatment media containing $\left[{ }^{35} \mathrm{~S}\right]$ methionine for a 15 -min pulse. The cells were washed and chased in treatment media containing $10 \mathrm{mM}$ unlabeled L-methionine for $15 \mathrm{~min}$. Intracellular and extracellu-

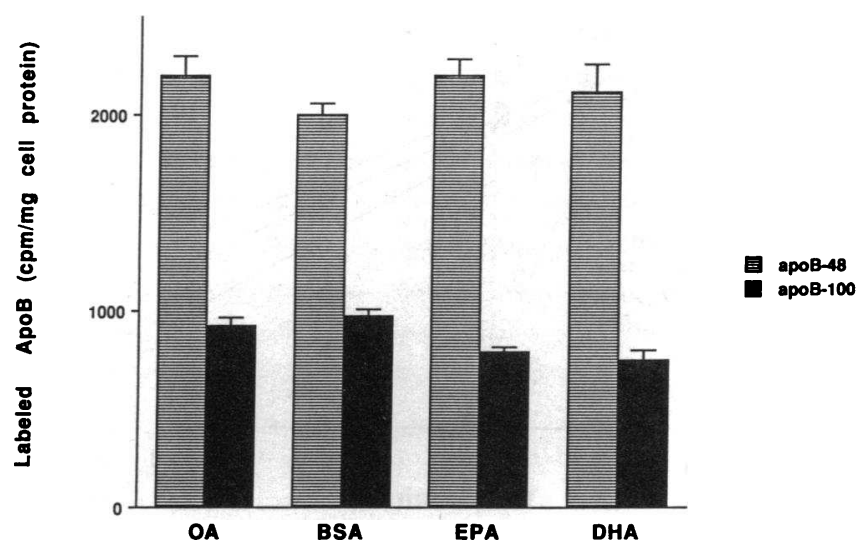

Figure 3. FA effects on the initial synthetic rate of apoB. Rat hepatocytes were incubated with either BSA alone or FA-BSA complexes for $4 \mathrm{~h}$. Without changing medium, cells were pulse-labeled for 15 min by adding $\left[{ }^{35} \mathrm{~S}\right]$ methionine as described in Methods. Labeled apoB species were isolated and processed as in Fig. 2. Labeling of apoB was quantitated by scintillation counting of the appropriate bands removed from the gel. Data for each labeled apoB species are expressed as mean $( \pm \mathrm{SEM}) \mathrm{cpm} / \mathrm{mg}$ cell protein. Results shown are from three separate experiments, each one performed in triplicate. 


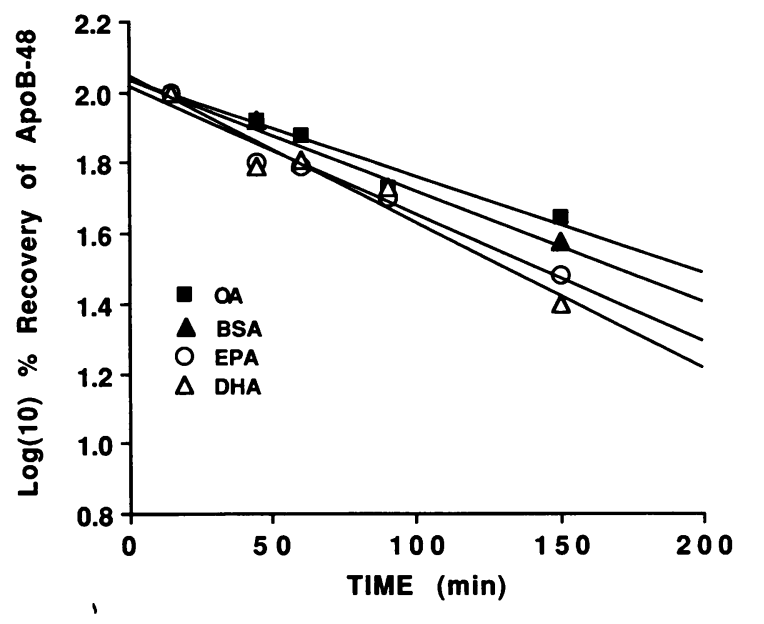

Table III. Regression Analysis of ApoB Disappearance from Cells

\begin{tabular}{lllrl}
\hline & Treatment & Slope & $t_{1 / 2}$ & $r$-value \\
\hline \multirow{4}{*}{ ApoB48 } & & $\min ^{-1}$ & $\min$ & \\
& OA & -0.0027 & 111 & -0.97 \\
& BSA & -0.0032 & 94 & -0.98 \\
& EPA & $-0.0036^{*}$ & 84 & -0.98 \\
ApoB100 & DHA & $-0.0042^{*}$ & 72 & -0.98 \\
& OA & -0.0034 & 89 & -0.95 \\
& BSA & $-0.0047^{*}$ & 64 & -0.99 \\
& EPA & $-0.0047^{*}$ & 64 & -0.99 \\
ApoB $_{\text {total }}$ & DHA & $-0.0056^{*}$ & 54 & -0.99 \\
& OA & -0.0029 & 104 & -0.99 \\
& BSA & $-0.0035^{*}$ & 86 & -0.99 \\
& EPA & $-0.0039^{*}$ & 77 & -0.99 \\
& DHA & $-0.0046^{*}$ & 65 & -0.99 \\
& & & & \\
\hline
\end{tabular}

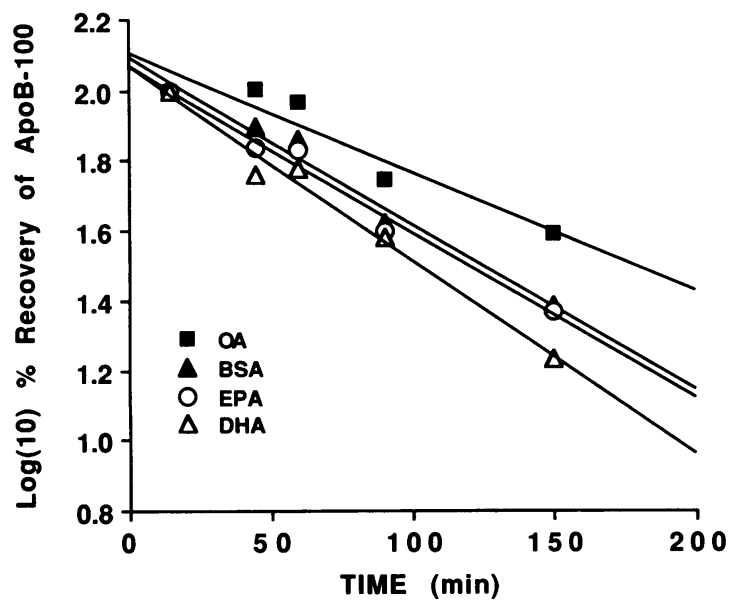

Cellular recovery data, as percentages of 15 -min values, were $\log _{10}$ transformed and fit to straight lines by linear regression analysis (Fig. 4). For each incubation condition, the slope, $t_{1 / 2}$, and correlation coefficient ( $r$-value) are shown for each apoB species and total apoB. The $t_{1 / 2}$ values were calculated by the standard equation: $t_{1 / 2}=\left(\log _{10}\right.$ $2) /\left(-\right.$ slope). ${ }^{*}$ Significantly different from slope for OA group $(P$ $<0.02$ ).

lar apoB were then measured by immunoprecipitation and SDS-PAGE analysis.

The amount of label incorporated into intracellular apoB at the end of the 15 min chase period was $~ 90 \%$ of the maximum value, similar to published results $(15,16)$. Secretion of radiolabeled apoB was not detected at the end of the chase period, consistent with the evidence that it takes $\sim \mathbf{4 0} \mathrm{min}$ for newly synthesized apoB to appear in conditioned medium ( 15 , $16,25)$. Relative initial rates of synthesis in each treatment condition could therefore be reliably estimated from the amount of $\left[{ }^{35} \mathrm{~S}\right]$ methionine incorporated into the apoB species because of the high degree of labeling of intracellular apoB after the brief pulse of isotope and the confinment of newly synthesized apoB within the cell at the end of the experiment.

As shown in Fig. 3, the incorporation of $\left[{ }^{35} \mathrm{~S}\right]$ methionine into intracellular apoB100 and apoB48 was similar among all treatment groups, indicating there were no significant $(P$ $>0.1$ ) effects of BSA, OA, EPA, or DHA on the initial synthetic rates of both species of apoB.

Pulse-chase studies of apoB metabolism. To determine the effects of EPA and DHA on the degradation of apoB, the duration of the chase period was lengthened and the recovery of labeled apoB from cell lysates and conditioned media measured over time. As shown in Fig. 4 and Table III, in each treatment group the decay of intracellular apoB48, apoB100, or total apoB was a first-order kinetic process and the rate of decay was faster for apoB 100 than for apoB48, consistent with previous studies using rat hepatocytes maintained in media

Figure 4. FA effects on the disappearance of cellular apoB. Rat hepatocytes were treated as in Fig. 3, except that after pulse-labeling with $\left[{ }^{35} \mathrm{~S}\right]$ methionine, media were changed to remove label, and incubations were continued for the indicated times in treatment media containing an excess of unlabeled methionine. At the end of each chase period, labeled apoB was isolated from cell lysate by immunoprecipitation. Quantitation of labeled apoB was done as in Fig. 3. For each treatment condition, the percent of labeled apoB recovered relative to the 15 -min time point was calculated, $\log$ transformed, and the data $\left(\log _{10} \%\right.$ recovery over time $)$ modeled by linear regression without

force-fitting the lines. Results shown are from six separate experiments, each done in duplicate or triplicate. The panels show the disappearance from cells of (top) labeled apoB48, (middle) apoB100, and (bottom) apo $\mathrm{B}_{\text {total }}$. The treatment conditions corresponding to each line are as indicated. 

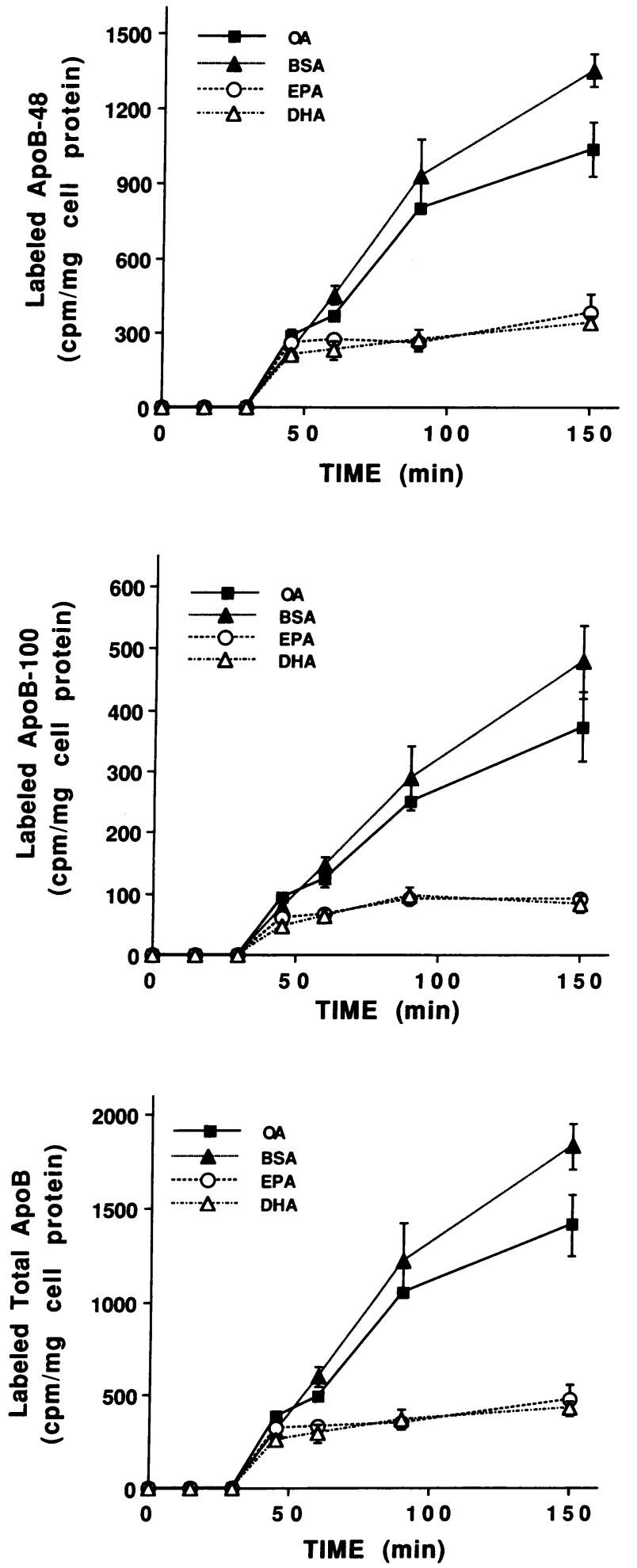

Figure 5. FA effects on the appearance of apoB in medium. Rat hepatocytes were treated as in Fig. 4, except that at the end of each chase period, labeled apoB was isolated from cell medium by immunoprecipitation. Quantitation of labeled apoB was done as in Fig. 3. The appearance over time of labeled apoB48, apoB100, and $\operatorname{apoB}_{\text {total }}$ (mean \pm SEM) are shown in top, middle, and bottom panels, respectively. Results shown are from six separate experiments, each done in duplicate or triplicate. The treatment conditions corresponding to each line are as indicated. that did not contain FA-BSA complexes $(15,16)$. Comparisons among the treatment groups revealed that apoB48, apoB100, and total apoB disappeared from EPA- and DHAtreated cells more rapidly than from OA-treated cells (Fig. 4). This impression was confirmed by analysis of the slopes of the regression lines (Table III). The difference was observable by the 45-min time point and became more apparent as the chase period lengthened.

In contrast to hepatocytes treated with OA or BSA, in hepatocytes incubated with EPA and DHA, intracellular apoB decreased over time with no corresponding increase in medium apoB48, apoB100, or total apoB (Fig. 5). Thus, the total apoB in the system (the sum of intra- and extracellular apoB) by 45 min of chase was decreased in the cells treated with n-3 fatty acids. Addition of protease inhibitors to the media did not affect the results, indicating that extracellular degradation of apoB had not occurred.

An example of primary data obtained after $150 \mathrm{~min}$ of chase is shown in Fig. 6. As compared to the OA and BSA groups, EPA and DHA treated cells had both reduced extracellular (Fig. 6, left) and intracellular (Fig. 6, right) levels of labeled apoB. These results (Fig. 4-6) indicate, then, that in the presence of n-3 fatty acids, relative to OA and BSA, substantially more of the newly synthesized apoB species was degraded.

To examine quantitatively the rapidity and magnitude of the effects of EPA and DHA on the intracellular degradation of apoB in hepatocytes, we calculated the recoveries of labeled apoB after various chase periods relative to the peak level of isotope incorporation. These data are summarized in Table IV and Fig. 7, and confirm the data displayed in Figs. 4-6: In the presence of n-3 fatty acids, there was an early increase in the degradation of 'apoB that was maintained during the longer chase periods. By 150 min of chase, the amount of degradation in the $\mathrm{n}-3$ fatty acid groups was at least twice that in the $\mathrm{OA}$ and BSA groups $(P<0.01)$. Although the intracellular steady-state levels of apoB in the BSA group were lower than those of the OA group (Fig. 2, Table I), indicating a smaller intracellular

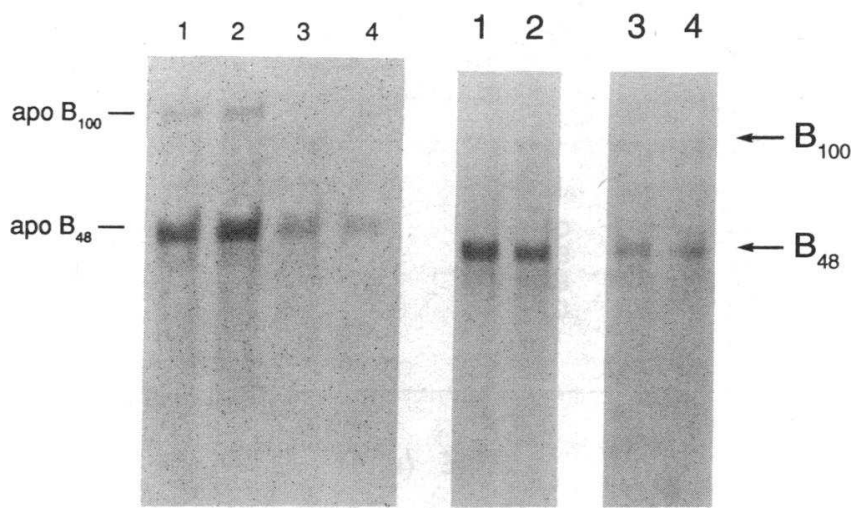

Figure 6. FA effects on the amount of pulse-labeled apoB in the cell and medium after 150 min of chase. Rat hepatocytes were treated as in Fig. 4. Labeled apoB was isolated after a 150-min chase period and fluorographic signals after gel electrophoresis obtained, as in Fig. 2. Markers on left and right indicate the expected positions of the apoB species. Left: Analysis of conditioned media after treatment with 1 , OA; 2, BSA; 3, EPA; 4, DHA. Right: Analysis of corresponding cell lysates. 
Table IV. Effects of BSA and FA-BSA Complexes on the Recovery of Labeled ApoB Species from Cell and Medium after 45- to 150-min Chase Periods

\begin{tabular}{|c|c|c|c|c|c|c|c|c|c|}
\hline \multirow[b]{4}{*}{ Treatment } & \multicolumn{9}{|c|}{ Chase times } \\
\hline & \multicolumn{9}{|c|}{$\min$} \\
\hline & \multicolumn{3}{|c|}{45} & \multicolumn{3}{|c|}{90} & \multicolumn{3}{|c|}{150} \\
\hline & apoB100 & apoB48 & $\mathrm{apoB}_{\mathrm{T}}{ }^{*}$ & apoB 100 & apoB48 & $\mathrm{apoB}_{\mathrm{T}}{ }^{*}$ & apoB100 & apoB48 & $\operatorname{apoB}_{\mathrm{T}}^{*}$ \\
\hline & \multicolumn{9}{|c|}{$\%$} \\
\hline $\mathrm{OA}$ & $103 \pm 9$ & $100 \pm 9$ & $101 \pm 9$ & $80 \pm 9$ & $77 \pm 9$ & $79 \pm 9$ & $73 \pm 12$ & $74 \pm 19$ & $73 \pm 9$ \\
\hline BSA & $94 \pm 3$ & $91 \pm 3$ & $91 \pm 3$ & $81 \pm 5$ & $78 \pm 4$ & $79 \pm 4$ & $77 \pm 3$ & $77 \pm 7$ & $77 \pm 5$ \\
\hline EPA & $78 \pm 3$ & $85 \pm 4$ & $83 \pm 4$ & $50 \pm 5$ & $54 \pm 5$ & $53 \pm 5$ & $29 \pm 4$ & $40 \pm 1$ & $35 \pm 4$ \\
\hline DHA & $64 \pm 9$ & $73 \pm 10$ & $71 \pm 10$ & $49 \pm 4$ & $54 \pm 8$ & $53 \pm 6$ & $25 \pm 4$ & $32 \pm 4$ & $30 \pm 1$ \\
\hline
\end{tabular}

Rat hepatocytes were treated as described in Fig. 3. Initial quantitation of the recovery of labeled total apoB $\left(\operatorname{apoB}_{\mathrm{T}}\right)$ was done by scintillation counting of bands from gels used to separate apoB species immunoprecipitated from cell lysates and media. The recovery data were then converted to the mean percentage $( \pm \mathrm{SD})$ of the peak value of $\left[{ }^{35} \mathrm{~S}\right]$ methionine incorporated into the appropriate apoB species. Results shown are from six separate experiments, each done in duplicate or triplicate. ${ }^{*}$ Statistical analysis revealed that, at each time point, the recovery of labeled $\mathrm{apoB}_{\mathrm{T}}$ was lower in the EPA and DHA compared to the OA and BSA groups (45 min, $P<0.05 ; 90 \mathrm{~min}, P<0.02 ; 150 \mathrm{~min}, P<0.002$ ).

pool, the overall degradation of apoB was the same. This can be explained by the apparent higher fractional secretion of apoB in the BSA group (compare the lines for OA and BSA in Figs. 4 and 5; see also Discussion).

The data plotted in Fig. 5 were also examined for differential effects of the n-3 fatty acids on the two species of apoB. The average ratio of labeled apoB 100 to apoB48 in the media of EPA- and DHA-treated cells after $150 \mathrm{~min}$ of chase $(0.24)$ was significantly lower $(P<0.001)$ than the corresponding value for the OA and BSA groups (0.36). Thus, of the two species of apoB, the secretion of labeled apoB 100 was apparently preferentially affected.

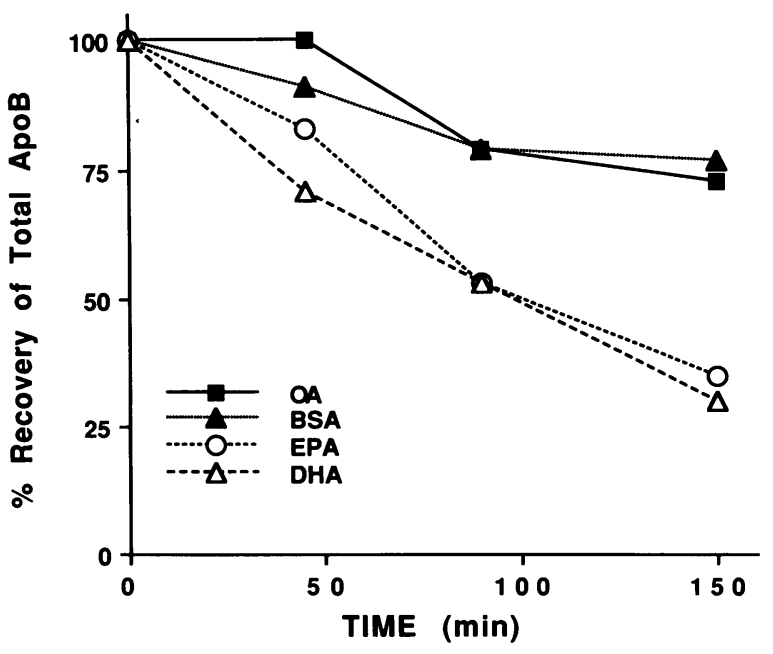

Figure 7. FA effects on the total recovery of labeled apoB after pulse-labeling. Data for the total labeled apoB (sum of apoB 100 and apoB48 in the cell and medium) measured at the end of each chase period were taken from Table IV. The $y$-axis represents the recovery of labeled apoB as the mean percentage of the peak value of $\left[{ }^{35} \mathrm{~S}\right]-$ methionine incorporated into apoB. The $x$-axis is the duration of the chase period. At $45 \mathrm{~min}$, the percent recovery in the OA group $(101 \pm 9)$ was slightly higher than that in the BSA group $(91 \pm 3, P$ $<0.05$ ).
Effects of cycloheximide on apoB degradation. Preliminary experiments indicated that $10 \mu \mathrm{g} / \mathrm{ml}$ of cycloheximide inhibited over $95 \%$ of protein synthesis for at least $4 \mathrm{~h}$ without affecting cell viability, as previously reported (26).

The effects of cycloheximide on the changes associated with the $\mathrm{n}-3$ fatty acids were explored in two different experimental designs in which the inhibition of protein synthesis was either

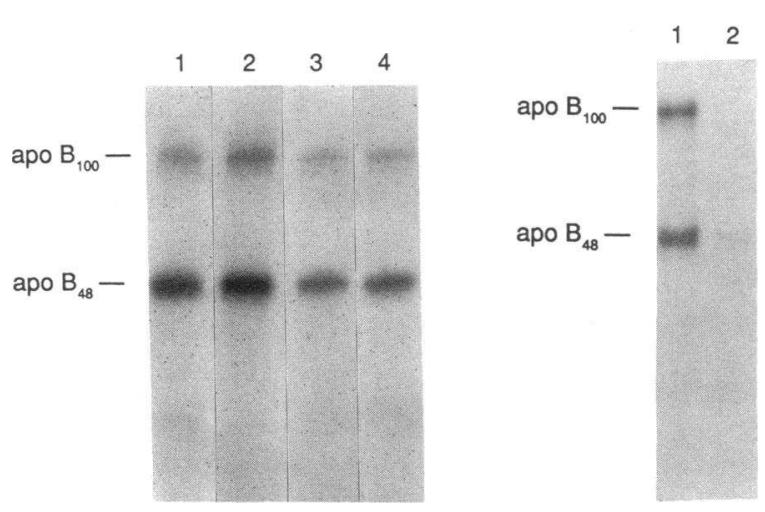

Figure 8. Effects of cycloheximide on apoB newly secreted by hepatocytes incubated with different FA. Left: Rat hepatocytes were incubated overnight in serum-free medium containing [ $\left.{ }^{35} \mathrm{~S}\right]-$ methionine. In the morning, the different treatment media were applied. Media contained cycloheximide, unlabeled methionine, and either BSA alone or FA-BSA complexes. After a 3-h incubation, labeled apoB was isolated from conditioned media by immunoprecipitation and processed as in Fig. 2. The resulting fluorographic signals are displayed. Markers on left are the expected positions of the apoB species. The FA treatment conditions for each lane were 1, OA; 2, BSA; 3, EPA; 4, DHA. The ratio of labeled apoB100/apoB48, as determined by scintillation counting of bands (Methods), for each lane was $0.28,0.43,0.24$, and 0.23 , respectively. Right : Rat hepatocytes were incubated for $4 \mathrm{~h}$ in the presence of $\left[{ }^{35} \mathrm{~S}\right]$ methionine and either an OA- or EPA-BSA complex. After washing, cells were incubated for $3 \mathrm{~h}$ in medium containing cycloheximide, unlabeled methionine, and the appropriate FA-BSA complex. The remaining procedures were identical to those in the left panel. The FA treatment conditions for each lane were $1, \mathrm{OA} ; 2$, EPA. 
concurrent with or followed the fatty acid treatment, as described in Methods. At the conclusion of both types of experiments, immunoprecipitation analysis and electrophoresis were performed as above, and quantitative information obtained by cutting out the apoB-related gel bands and assaying the incorporated radioactivity by scintillation counting.

As shown in Fig. 8, left, when cycloheximide was added concurrent with fatty acid treatment (first design), secretion of radiolabeled apoB was still significantly decreased by EPA and DHA relative to OA or BSA. As compared to the results in the OA group, apoB 100 and apoB48 were decreased by $38 \%$ and $46 \%$, respectively, in the presence of EPA, and $30 \%$ and $42 \%$, respectively, in the presence of DHA $(P<0.05, n=3)$. In experiments in which cycloheximide was added after treatment with fatty acids had begun (second design), as compared to $\mathrm{OA}$, the reduction in the secetion of newly synthesized apoB in the presence of EPA was even more dramatic (Fig. 8, right; as compared to $\mathrm{OA}$, the decreases in apoB100 and apoB48 were $85 \%$ and $72 \%$, respectively). It is clear from both experimental designs that active protein synthesis was not required to demonstrate the effects of the n-3 fatty acids. That the decrease observed when cycloheximide was added after fatty acid treatment had begun was greater was a consequence of the reduced steady-state level of apoB in the cells that resulted from the exposure to EPA before cycloheximide was added to the medium. Since EPA was continued in the incubation medium, the intracellular level of apoB continued to fall. In contrast, in the first design, at the time cycloheximide was added the steady-state levels of apoB in the cells were higher, since labeling was done in the absence of the fatty acid treatments. Overall, these results indicated that both the initiation and the maintenance of the effects of $n-3$ fatty acids on the secretion of newly synthesized apoB were relatively independent of protein synthesis.

\section{Discussion}

The central importance of apoB to the ability of the liver to secrete TG-rich lipoproteins has been long appreciated from both experimental studies (for example, 26) and the characterization of patients with abetalipoproteinemia (27). The impairment of this ability by EPA and DHA without limitation of TG synthesis (Fig. 1) suggested that the apoB available for lipoprotein production may have been reduced by changes in its synthesis or degradation. We also considered the possibility that impaired secretion of apoB, which resulted in its intracellular accumulation, was an explanation for our results.

After labeling cells with $\left[{ }^{35} \mathrm{~S}\right]$ methionine to steady-state, it was apparent that rather than accumulating in cells incubated with EPA and DHA, there were reduced levels of both apoB48 and apoB100, as compared to OA (Fig. 2, Table I). The initial synthetic rates of $a p o B$ in the different treatment groups were comparable (Fig. 3), consistent with the constitutive levels of apoB mRNA (Table II). Based on the steady-state and synthetic studies, the most likely explanation for our results was that in the presence of EPA and DHA, the degradation of apoB was increased, and a series of pulse-chase experiments was undertaken to test this possibility directly.

After pulse-labeling with $\left[{ }^{35} \mathrm{~S}\right]$ methionine, the recoveries of apoB100 and apoB48 during the chase periods in either compartment (cell lysate, conditioned medium) were considerably decreased when cells were incubated with EPA or DHA (Figs. 4-7; Table IV). The differences in cellular apoB among treatments could be seen as early as $45 \mathrm{~min}$ of chase and increased over the course of the 150-min chase period. The effects of $n-3$ fatty acids on secreted apoB appeared as early as 60 min of chase and persisted through the 90 - and 150 -min periods. This lag between detecting differences in cellular and secreted apoB was expected because of the well-known delay in the appearance of newly synthesized secretory proteins into the medium. By 150 min of chase, as compared to the results for the OA and BSA groups, in the EPA and DHA groups, only approximately half as much labeled apoB was recovered in the cells and media (Fig. 7, Table IV). Thus, the effects of EPA and DHA on the secretion of newly synthesized apoB were quantitatively accounted for by increased intracellular apoB degradation.

The effects of EPA and DHA on apoB degradation did not require active protein synthesis, as demonstrated by the experiments with cycloheximide (Fig. 8). Besides showing that both the induction and maintenance of the effects were still detectable, in spite of a $>95 \%$ reduction in new protein synthesis, these data support the conclusion that $n-3$ fatty acids exert their effects not on the synthesis but on the intracellular degradation of apoB.

From the pulse-chase and steady-state data we were also able to analyze other aspects of apoB metabolism under the different treatment conditions. As compared to the OA group, in the BSA group the cellular content of steady-state labeled apoB was lower (Table I, Fig. 2), but in the pulse-chase experiment, the accumulation of labeled apoB in the medium was greater (Fig. 5) and the recovery of apoB was similar ( Table IV, Fig. 7). Overall, then, the data are consistent with a shorter intracellular half-life of apoB in the BSA group, which was indeed the case (Table III, Fig. 4), indicating a higher fractional rate of apoB secretion. This would ultimately result in a smaller intracellular pool of apoB in the presence of BSA, just as we found (Table I, Fig. 2). The difference in the rate of apoB secretion between the two groups could be due to a primary increase in the BSA group, or, alternatively, a decrease in the OA group reflecting the time required to assemble or secrete relatively TG-rich apoB-containing particles.

In the initial experiment (Fig. 1) significant differences were not visible between the OA and BSA groups in the accumulation in medium of newly synthesized apoB. This may be explained by the fact that the differences were comparatively small and would not have been reliably detected by fluorography. In addition, the designs of the two experiments were not identical (Fig. 1, accumulation in medium over $4 \mathrm{~h}$, with label always present; Fig. 5, accumulation over $150 \mathrm{~min}$, after pulselabeling), which may have had some influence on the results. Finally, there may have been a small degree of biological variability between experiments.

In the EPA and DHA groups, interpretation of the intracellular half-life of apoB is more complicated.. Although in the EPA, DHA, and BSA groups total apoB disappeared more rapidly from the cells, as compared to the OA group (Fig. 4, bottom; Table III), in contrast to the BSA group, increased apoB degradation in the n-3 fatty acid groups contributed significantly to this accelerated intracellular decay. While it may be possible that differential effects of EPA and DHA on apoB secretory rates were involved in the shorter intracellular halflife of apoB100 vs. apoB48 ( Table III) and the reduced average 
ratio of labeled apoB 100 to apoB48 observed in the media at 150 min of chase ( 0.24 vs. 0.36 for the OA and BSA groups, as noted in Results), it is more likely that some preference for apoB 100 in the stimulated degradative process was responsible: as calculated from the data in Table IV, after $150 \mathrm{~min}$ of chase, in the n-3 fatty acid groups the average recovery of apoB100 was less than that of apoB48 (36\% vs. $47 \%$ of the corresponding average recoveries in the OA and BSA groups).

Our results can be compared to those of recent studies. Sparks and Sparks have reported (16) that there was a stimulation by insulin of the degradation of newly synthesized apoB100 and apoB48 that favored the apoB100 species. It has also been recently reported that in hepatocytes of rats that had consumed diets enriched with n-3 fatty acids, there may have been increased degradation of apoB (28). This was suggested by the presence of short peptides in the conditioned media reactive with an antibody directed against rat apoB. Lang and Davis (6) have reported that after steady-state labeling of rat primary hepatocytes in the presence of FA-BSA complexes, although there were reductions in the secretion of newly synthesized apoB associated with EPA and DHA, there was no significant difference between $n-3$ fatty acid and OA treatments in the cellular levels of apoB labeled to steady-state. However, the cellular measurements were rather variable and effects on the order of those observed in the present work may have been obscured. Another potential factor contributing to the negative results of Lang and Davis was the longer treatment period they used ( 18 vs. $4 \mathrm{~h}$ ).

In HepG2 cells, Dixon et al. (29) showed that relative to BSA, OA stimulated apoB secretion by 2.5 -fold primarily by inhibiting the intracellular degradation of apoB. The HepG2 results are not consistent with the present and previous studies in hepatocytes isolated from ad-lib fed rats $(6,26)$ in which the addition of OA to cultures of those cells did not result in an increased accumulation of apoB in the conditioned medium. The reasons for this discrepancy are not clear, but may related to differences in the cell types. For example, in the absence of added free fatty acids, true VLDL particles are not produced by HepG2 cells. Also, as compared to primary cells, they have additional energy requirements that may be partially met by using exogenous fatty acids as primarily fuel sources. Perhaps HepG2 cells resemble hepatocytes from fasted rats, which differ dramatically from hepatocytes from ad-lib fed rats by increasing their secretion of $a p o B$ in response to oleic acid (30).

Although Borchardt and Davis (15) reported in 1987 that a large proportion of newly synthesized apoB can be degraded intracellularly in rat hepatocytes, indicating that apoB is subject to a highly active sorting process, this process as well as other aspects of cellular apoB-containing particle metabolism remain incompletely documented or controversial. There are divergent views on such matters as the site of initial lipid transfer (the rough endoplasmic reticulum [31, 32] vs. the smooth endoplasmic reticulum $[25,33])$ and the organelle in which apoB resides the longest (endoplasmic reticulum [15, 34 ] vs. Golgi apparatus [35, 36]); however, in recent reports there is good evidence that during translation, apoB is not completely translocated across the endoplasmic reticulum membrane and remains membrane-bound $(31,32,37-39)$. Presumably, this apoB could be targeted to either a lipoprotein assembly/secretion pathway or to degradation.

The n-3 fatty acids could exert their effects by either interfer- ing with lipoprotein assembly and targeting apoB to a degradative pathway, or directly stimulating the degradation of apoB. Potential effects of EPA and DHA would include induced changes in the metabolic pathways of cholesterol, cholesteryl esters, triglycerides, and phospholipids, in that decreases in the synthesis or availability of these key lipoprotein components are factors known to have the potential to reduce apoB-containing particle secretion (for example, see references 40-42). Also to be considered is the possibility that in the presence of EPA and DHA, apoB is not appropriately co- or post-translationally modified. For example, apoB in rat and man is fatty acylated $(43,44)$. Acylation can affect both the ability of proteins to cross membranes and the folding of proteins (45). N-3 fatty acids might influence the acylation process in a variety of ways that promote apoB degradation or interfere with lipoprotein assembly.

It is clear that more data will be needed to support any potential model for the mechanism by which n-3 fatty acids lead to increased intracellular apoB degradation. In addition, the compartment of the cell in which the increased degradation occurs needs to be identified by cell fractionation methods, in case the $\operatorname{step}(\mathrm{s})$ affected by EPA and DHA occur outside the $E R$, for example, during maturation of nascent lipoproteins in the Golgi.

Whatever the nature or location of the mechanism, based on the experiments using cycloheximide, it does not seem to require active protein synthesis. It must also be rapid in onset and quickly reversible, because in pulse-chase experiments in which fatty acids were omitted during the chase periods no significant effects were observed: although n-3 fatty acids were present for $4 \mathrm{~h}$ before the pulse of $\left[{ }^{35} \mathrm{~S}\right]$ methionine, if they were subsequently withdrawn during the chase period, by the end of $60 \mathrm{~min}$ the recovery of apoB was comparable to that in the OA and BSA groups $(87.8 \%$ for the EPA and DHA groups vs. $88.2 \%$ for the OA and BSA groups).

In summary, our results clearly demonstrate that in the rat hepatocyte, the decreased secretion of newly synthesized apoB in the presence of the $n-3$ fatty acids EPA and DHA is a consequence of increased intracellular degradation of both apoB 100 and apoB48. Thus, apoB degradation is not a constitutive process, but can be regulated by a nutritional factor.

\section{Acknowledgments}

We thank Dr. Julian B. Marsh for his continued interest, many helpful suggestions, and critical reading of the manuscript. The advice of Drs. Janet D. Sparks, Kevin Jon Williams, and Michael C. Phillips is also acknowledged. We also thank Ms. Charlotte Veloski for her contributions to the initial experiments and Drs. Daniel L. Sparks and George $H$. Rothblat for their help in the computer analysis of data.

This work was supported by funds from the National Institutes of Health (HL 22633), the W. W. Smith Charitable Trust, and the Howard Heinz Endowment.

\section{References}

1. Harris, W. S. 1989. Fish oils and plasma lipid and lipoprotein metabolism in humans: a critical review. J. Lipid Res. 30:785-807.

2. Nestel, P. L. 1990. Effects of n-3 fatty acids on lipid metabolism. Annu. Rev. Nutr. 10:149-168.

3. Rustan, A. C., J. O. Nossen, E. N. Christiansen, and C. A. Drevon. 1988. Eicosapentaenoic acid reduces hepatic synthesis and secretion of triacylglycerol 
by decreasing the activity of acylcoenzyme A: 1,2-diacylglycerol acyltransferase. J. Lipid Res. 29:1417-1426.

4. Weintraub, M. S., R. Zechner, A. Brown, S. Eisenberg, and J. L. Breslow. 1988. Dietary polyunsaturated fats of the W-6 and W-3 series reduce postprandial lipoprotein levels. J. Clin. Invest. 82:1884-1893.

5. Ventura, M. A., L. A. Woollett, and D. K. Spady. 1989. Dietary fish oil stimulates hepatic low density lipoprotein transport in the rat. J. Clin. Invest. 84:528-537.

6. Lang, C. A., and R. A. Davis. 1990. Fish oil fatty acids impair VLDL assembly and/or secretion by cultured rat hepatocytes. J. Lipid Res. 31:20792086.

7. Homan, R., J. E. Grossman, and H. J. Pownall. 1991. Differential effects of eicosapentaenoic acid and oleic acid on lipid synthesis and secretion by HepG2 cells. J. Lipid Res. 32:231-241.

8. Wong, S. H., E. A. Fisher, and J. B. Marsh. 1989. Effects of eicosapentaenoic and docosahexaenoic acids on apoprotein B mRNA and secretion of very low density lipoprotein in HepG2 cells. Arteriosclerosis. 9:836-841.

9. Sparks, C. E., and J. B. Marsh. 1981. Metabolic heterogeneity of apolipoprotein B in the rat. J. Lipid Res. 22:519-527.

10. Elovson, J., Y. O. Huang, N. Baker, and R. Kannan. 1981. Apolipoprotein B is structurally and metabolically heterogeneous in the rat. Proc. Natl. Acad. Sci. USA. 78:156-161.

11. Higuchi, K., A. V. Hospattankar, S. W. Law, N. Meglin, J. Cortright, and H. B. Brewer, Jr. 1988. Human apolipoprotein B (apoB) mRNA: Identification of two distinct apoB mRNAs, an mRNA with the apoB-100 sequence and an apoB mRNA containing a premature in-frame translational stop codon, in both liver and intestine. Proc. Natl. Acad. Sci. USA. 85:1772-1776.

12. Davidson, N. O., L. M. Powell, S. C. Wallis, and J. Scott. 1988. Thyroid hormone modulates the introduction of a stop codon in rat liver apolipoprotein B mRNA. J. Biol. Chem. 263:13482-13485.

13. Sparks, C. E., and J. B. Marsh. 1981. Analysis of lipoprotein apoproteins by SDS-gel filtration column chromatography. J. Lipid Res. 22:514-518.

14. Harlow, D. E., and D. Lane. 1988. Antibodies-A Laboratory Manual. Cold Spring Harbor Laboratory, Cold Spring Harbor, NY. 471-506.

15. Borchardt, R. A., and R. A. Davis. 1987. Intrahepatic assembly of very low density lipoproteins. J. Biol. Chem. 262:16394-16402.

16. Sparks, J. D., and C. E. Sparks. 1990. Insulin modulation of hepatic synthesis and secretion of apolipoprotein B by rat hepatocytes. J. Biol. Chem. 265:8854-8862.

17. Maguire, G. F., M. Lee, and P. W. Connelly. 1989. Sodium dodecyl sulfate-glycerol polyacrylamide slab gel electrophoresis for the resolution of apolipoproteins. J. Lipid Res. 30:757-761.

18. Williams, D. L., and P. A. Dawson. 1986. Immunochemical measurement of apolipoprotein synthesis in cell and organ cultures. Methods Enzymol. 129:254-271.

19. Han, J. H., C. Stratowa, and W. J. Rutter. 1987. Isolation of full-length putative rat lysophospholipase cDNA using improved methods for mRNA isolation and cDNA cloning. Biochemistry. 26:1617-1625.

20. Zolfaghari, R., E. H. Harrison, A. C. Ross, and E. A. Fisher. 1989. Expression in Xenopus oocytes of rat liver mRNA coding for a bile salt-dependent cholesteryl ester hydrolase. Proc. Natl. Acad. Sci. USA. 86:6913-6916.

21. Feinberg, A., and B. Vogelstein. 1984. A technique for radiolabelling DNA. Anal. Biochem. 137:266-267.

22. Lowry, O. H., N. J. Rosebrough, A. L. Farr, and R. J. Randall. 1951. Protein measurement with the Folin phenol reagent. J. Biol. Chem. 193:265275.

23. Bass, J., E. A. Fisher, M. M. Prack, D. L. Williams, and J. B. Marsh. 1991. Macrophages from nephrotic rats regulate apolipoprotein $E$ biosynthesis and cholesterol content independently. J. Clin. Invest. 87:470-475.

24. Kleinbaum, D. G., L. L. Kupper, and K. E. Muller. 1988. Applied Regression Analysis and Other Multivariable Methods. PWS-Kent, Boston, MA. 41-79.

25. Janero, D. R., and M. D. Lane. 1983 . Sequential assembly of very low density lipoprotein apolipoproteins, triacylglycerol, and phosphoglycerides by the intact liver cell. J. Biol. Chem. 258:14496-14504.

26. Davis, R. A., and J. R. Boogaerts. 1982. Intrahepatic assembly of very low density lipoproteins. J. Biol. Chem. 257:10908-10913.

27. Stanbury, J. B., J. B. Wyngaarden, D. S. Fredrickson, J. L. Goldstein, and M. S. Brown. 1983. The Metabolic Basis of Inherited Disease. McGraw Hill, Inc. New York. 597-605.

28. Ribeiro, A., M. Mangeney, P. Cardot, C. Loriette, Y. Rayssiguier, J. Chambaz, and G. Bereziat. 1991. Effect of dietary fish oil and corn oil on lipid metabolism and apolipoprotein gene expression by rat liver. Eur. J. Biochem. 196:499-507.

29. Dixon, J. L., S. Furukawa, and H. N. Ginsberg. 1991. Oleate stimulates secretion of apolipoprotein B-containing lipoproteins from HepG2 cells by inhibiting early intracellular degradation of apolipoprotein B. J. Biol. Chem. 266:5080-5086.

30. Salam, W. H., H. G. Wilcox, and M. Heimberg. 1988. Effects of oleic acid on the biosynthesis of lipoprotein apoproteins and distribution into the very-lowdensity lipoprotein by the isolated perfused rat liver. Biochem. J. 251:809-816.

31. Chuck, S. L., Z. Yao, B. D. Blackhardt, B. J. McCarthy, and V. R. Lingappa. 1990. New variation on the translocation of proteins during the early biogenesis of apolipoprotein B. Nature (Lond.). 346:382-385.

32. Pease, R. J., G. B. Harrison, and J. Scott. 1991. Cotranslocational insertion of apolipoprotein $B$ into the inner leaflet of the endoplasmic reticulum. Nature (Lond.). 353:448-450.

33. Boren, J., M. Wettesten, A. Sjoberg, T. Thorlin, G. Bondjers, O. Wiklund, and S. Olofsson. 1990. The assembly and secretion of apo B100 containing lipoproteins in HepG2 cells. J. Biol. Chem. 265:10556-10564.

34. Davis, R. A., A. B. Prewett, D. C. Chan, J. J. Thompson, R. A. Borchardt, and W. R. Gallaher. 1989. Intrahepatic assembly of very low density lipoproteins: immunologic characterization of apolipoprotein B in lipoproteins and hepatic membrane fractions and its intracellular distribution. J. Lipid Res. 30:11851196.

35. Bamberger, M. J., and M. D. Lane. 1990. Possible role of the Golgi apparatus in the assembly of very low density lipoprotein. Proc. Natl. Acad. Sci. USA. 87:2390-2394.

36. Gibbons, G. F. 1990. Assembly and secretion of hepatic very low density lipoprotein. Biochem. J. 268:1-13.

37. Davis, R. A., R. N. Thrift, C. C. Wu, and K. E. Howell. 1990. Apolipoprotein $B$ is both integrated into and translocated across the endoplasmic reticulum membrane. J. Biol. Chem. 265:10005-10011.

38. Bostrom, K., M. Wettesten, J. Boren, G. Bondjers, O. Wiklund, and S. Olofsson. 1986. Pulse-chase studies of the synthesis and intracellular transport of apolipoprotein B-100 in HepG2 cells. J. Biol. Chem. 261:13800-13806.

39. Wong, L., and R. M. Pino. 1987. Biogenesis of very low density lipoproteins in rat liver: intracellular distribution of apolipoprotein B. Eur. J. Biochem. 164:357-367.

40. Khan, B., H. Wilcox, and M. Heimberg. 1989. Cholesterol is required for secetion of VLDL by rat liver. Biochem. J. 259:807-816.

41. Cianflone, K. M., Z. Yasruel, M. A. Rodriguez, D. Vas, and A. D. Sniderman. 1989. Regulation of apoB secretion from HepG2 cells: evidence for a critical role for cholesteryl ester synthesis in the response to a fatty acid challenge. $J$. Lipid Res. 31:2045-2055.

42. Yao, Z., and D. E. Vance. 1988. The active synthesis of phosphatidylcholine is required for very low density lipoprotein secretion from rat hepatocytes. $J$. Biol. Chem. 263:2998-3004.

43. Huang, G., D. M. Lee, and S. Singh. 1988. Identification of the thiol ester-linked lipids in apolipoprotein B. Biochemistry. 27:1395-1400.

44. Hoeg, J. M., M. S. Meng, R. Ronan, S. J. Demosky, Jr., and H. B. Brewer, Jr. 1988. Apolipoprotein B synthesized by HepG2 cells undergoes fatty acid acylation. J. Lipid Res. 29:1215-1220.

45. Grand, R. J. 1989. Acylation of viral and eukaryotic proteins. Biochem. J. 258:625-638. 